\title{
Laboratórios Empáticos
}

\author{
Emphatic labs
}

\author{
Cinthia Mendonça*
}

\begin{abstract}
RESUMO
O artigo trata de laboratórios que se dedicam à materialização de ideias por meio do trabalho colaborativo. $\mathrm{O}$ trabalho colaborativo que se pode encontrar nestes espaços faz referência a ideia de commons, isto é, através dele podemos encontrar compartilhamentos em diferentes níveis, sobretudo, através da criação de laços sociais, políticos, científicos e ainda a gestão de recursos. São espaços de experimentação (tecnosocial, artística ou científica) que não necessitam de uma estrutura rígida para serem eficientes; ao contrário, é criando dispositivos para destituir estruturas como essa que poderão ser empáticos e inclusivos. Os laboratórios, se pensados como instâncias mais corporificadas e menos institucionalizadas, podem funcionar como um dispositivo de proliferação de fluxos de informações, até que estas ganhem forma.
\end{abstract}

Palavras-chave: Trabalho Colaborativo; Commons; Espaços Empáticos.

\begin{abstract}
The article analyses laboratories dedicated to the collaborative materialization of ideas through collaborative work. These refer us to the concept of commons, the sharing of spaces that refer us to technosocial, artistic or scientific experimentation which avoids rigid structures. They thus produce social, political, and scientific ties as well as the management of resources and may become empathic and inclusive. These less institutionalized structures can stimulate the proliferation of information flows until these gain form.
\end{abstract}

Keywords: Collaborative Work; Commons; Empathic Spaces

Há algumas décadas que há notícias sobre laboratórios que se dedicam a materialização de ideias por meio do trabalho colaborativo. São espaços urbanos ou rurais, centrais ou periféricos, que promovem, por meio de diferentes dinâmicas, o acesso ao conhecimento de maneira horizontal, tendo como ponto de partida a necessidade de criar, desenvolver ou solucionar questões relativas a iniciativas cidadãs. Há quem diga que esses laboratórios estão experimentando novas formas de relacionar produção e trabalho, operando além da restrita lógica de capital material, privilegiando o desenvolvimento individual ou coletivo, o acesso ao conhecimento e o direito à experimentação. A base dessa estrutura é, sem dúvida, a colaboração. Porém, que qualidade de colaboração será essa?

\footnotetext{
* Doutoranda em Práticas Artísticas Contemporâneas na Uerj. Mestra em Belas Artes pela EBA-
} UFRJ. Telefone: +55 24 998910980. E-mail: cinthiamendonca@gmail.com. 
O trabalho colaborativo que se pode encontrar nesses espaços faz referencia a ideia de commons, isto é, por intermédio dele podemos encontrar compartilhamentos em diferentes níveis, sobretudo mediante a criação de laços sociais, políticos, científicos e, ainda, a gestão de recursos.

Nesse contexto, onde não há remuneração direta pelas horas de dedicação ao trabalho, o ato de colaborar está completamente desvinculado do contexto da dádiva gratuita, unilateral, que seria, segundo o antropólogo Eduardo Viveiros de Castro, um outro nome do poder absoluto, "quem dá de graça pede tudo em troca" (CASTRO, 2008, p. 179). A dinâmica de troca nesse contexto laboratorial parece bastante clara: quem dá espera receber em troca o diferencial, justamente aquilo que não tem, aquilo que o outro (indivíduos ou coletividade) pode oferecer com sua alteridade. Mas também o vínculo é moeda, e as relações construídas nesse contexto se dão em diferentes níveis de conexão. Por vezes são intermináveis, desdobrando-se em redes e mais redes.

Dentro dos contextos laboratoriais aos quais me refiro, o processo de criação, as relações e também o produto gerado a partir desse conjunto de coisas, poderão ser disseminados e compartilhados, replicados e adaptados a diferentes realidades, mantendo ou não sua forma inicial. A circulação da informação - assim como a circulação das relações, produzidas ali - é facilitada pelos próprios agentes dos laboratórios, sendo o produto, finalmente, apenas uma das tantas faces do processo de criação. Em muitos casos, esse produto, efetivamente, não é o mais importante e nem mesmo o ponto final. Ele é apenas um horizonte comum determinado para agenciar desejos e demandas, já que, para um coletivo de pessoas que trabalham em conjunto, o tempo e os interesses envolvidos são diversos. Podemos dizer que haverá sempre um horizonte comum, mas isso não implica na inexistência de outras tantas paisagens.

Não se pode negar que a proliferação dos espaços laboratoriais e, sobretudo, a maneira como estes lidam com seus fluxos de informação, colabora para a formação dos indivíduos, isto é, alimenta modos de ser e estar no mundo.

Sob a perspectiva de Gilbert Simondon, a informação pode ser compreendida para além daquilo que circula entre emissor e receptor, sendo pensada como algo relacional de troca significativa e intensiva. Segundo ele, a intensidade de informação poderia ser considerada também como uma rede, no sentido em que opera conexões expressivas do um e do múltiplo, criando correlação entre múltiplos e diferentes termos (SIMONDON, 2009). Ela funcionaria como um elemento transdutivo - próprio dos processos de individuação -, operando nos indivíduos e provocando a sua transformação. Isto é, um laboratório pode ser um lugar de transformação coletiva e individual, na medida em que se garanta o trânsito de informações de maneira livre e não opressora.

Para serem desenvolvidos, os projetos que chegam a um laboratório cidadão deixam de ser iniciativas propriamente individuais para se transformarem em ações coletivas de inserção territorial, social, cultural, reagindo às demandas que estão fora do núcleo do projeto, abrindo-se e tomando forma, para além do que foi previamente planejado, por meio da ação de forças externas a ele. Pode-se dizer que uma colaboradora e um colaborador atuam como atualizadores de ideias, fazendo os projetos passarem por transformações até que possam ser comuns. A pessoa que colabora é o outro que vem nos alimentar e alimentar-se desta relação, trazendo-nos crise e solução, fazendo-nos pensar para além de nós mesmos: um horizonte comum se constrói na presença de outros. 
Alguns modelos de laboratório fogem ao rigor dos espaços científicos tradicionais, abrindo-se às incertezas e às contaminações das forças externas a eles. Nesses casos, a exterioridade é ingrediente fundamental dos processos realizados ali. Para tanto, o espaço não está isolado de seu entorno, ao contrário, as tantas realidades e exterioridades entrarão e sairão desses lugares num fluxo contínuo de renovação de energias, troca de ideias, compartilhamento de dados, técnicas e tecnologias das mais diversas.

Esse seria o caso de laboratórios que se inserem em contextos comunitários a partir de iniciativas próprias das comunidades. Pensemos em uma sandbox, trazida do universo infantil, como curiosamente nos sugeriu, em um artigo, o pesquisador Ricardo Brazileiro. Pensemos então nessa caixa de areia instalada na grama de um jardim - convenientemente criada como espaço ideal para as experimentações. Como nos descreve Brazileiro "a sandbox pressupõe um conflito: dentro da caixa, a areia é um recurso. Fora dela, um transtorno. A areia fora da caixa não torna a grama uma praia, apenas destrói a paisagem. Por outro lado, a grama dentro da caixa é tratada como nociva" (BRAZILEIRO, 2016). Um laboratório aberto à comunidade operária justamente na criação de fissuras nessa sandbox. Os espaços de experimentação (tecnossocial, artística ou científica) não necessitam dessa estrutura para serem eficientes. Ao contrário, é criando dispositivos para destituir estruturas como essa que eles poderão ser empáticos e inclusivos.

A extrapolação da sandbox leva o ambiente a ser resiliente, isto é, a buscar sintropia o equilíbrio necessário para coexistência e a sobrevivência de diferentes sistemas diversos, vivos e não vivos.

Imaginemos: a ciência aberta e os laboratórios cidadãos podem funcionar como ecossistemas sintrópicos. Para isso, faz-se necessário trabalhar por uma inovação integral, inovando-se institucionalmente, suspendendo mecanismos de mercado onde eles não são úteis, enfatizando outras e novas economias, atentando ao design de fazeres. Isto é, colaborando efetivamente na transposição para uma nova economia que considere escalas moleculares, que deixe de ver a natureza apenas como recurso, que aproxime o consumo do bem-estar, que transforme - no caso sulamericano - o acesso à tecnologia em algo mais do que apenas o consumo passivo e alienante de aparatos. E que, finalmente, faça uma gestão e uma governança empática e cidadã.

O modelo sintrópico funcionaria como os sistemas agroflorestais, em que os manejos de árvores de grande porte, arbustos e ervas, junto com gêneros alimentícios como mandioca, abóbora, feijão, bananeira, entre outras espécies, vai tornando possível a coexistência entre todos, em diferentes graus e escalas de interação. Na relação de uma para outra, árvores e plantas servirão ora de sombra, ora de adubo, tornando o ambiente propício para a proliferação e o desenvolvimento do sistema.

Há também aquelas iniciativas que, por agirem dentro de uma cultura underground ou na maré contrária às demandas hegemônicas desafiam a coerção e a obediência. Esses espaços voltados para atender demandas de minorias políticas e de representação cidadã - iniciativas anticapitalistas, contra-hegemônicas, pósindustriais, não patriarcais e não normativas - têm poder de lançar uma perspectiva contra a alienação radical que poderes políticos e corporativos costumam promover no exercício de suas regras ou leis. Esse tipo de laboratório une aqueles que se sentem não incluídos nos modos de existência da economia neoliberal ou no sistema hegemônico de produção, inclusive de sentido. Os encontros realizados em laboratórios como esse podem fazer com que pessoas que possuem outros desejos 
ou necessidades encontrem estrutura para desenvolveram sua potência criativa, para que possam trabalhar sobre o que de fato as interessam. Por promover e proporcionar o acesso das tecnologias às minorias, uma iniciativa assim descentraliza o poder e desapropria o saber. Esse é o caso de laboratórios que recebem projetos e colaboradores vindos de iniciativas contraestatais ou contracorporativas, etnias indígenas, grupos de mulheres, grupos feministas, camponeses, caiçaras, quilombolas, pessoas trans, imigrantes, pessoas com diversidade funcional ou psíquica, entre outros.

Muitos desses laboratórios sustentam uma prática absolutamente experimental, tanto no que diz respeito à gestão quanto à execução, trabalhando a tecnologia de maneira bastante inclusiva, levando a cabo conceitos como colaboração, horizontalidade e escuta, baseados em princípios éticos muito próprios e, sobretudo, na empatia. Assim, a retomada ou a tomada de sentido mobiliza essa espécie de laboratório.

Para descrever os processos de colaboração e empatia presentes nessas iniciativas, recorro à lógica ameríndia desta terra de Caetés, Tupinambás e tantos outros povos canibais. O canibalismo da costa brasileira teve fundamental importância na organização social de diferentes culturas indígenas e, como nos assegura Viveiros de Castro, esta seria a verdadeira metafísica desses povos extramodernos (CASTRO, 2016).

A partir do pensamento modernista brasileiro, o canibalismo foi estetizado e assimilado como o ato de se alimentar da cultura externa, isto é, não se deve recusar a cultura estrangeira, pois esta pode ser elaborada, digerida, deglutida para, em seguida, ser expressa: "Só me interessa o que não é meu" (ANDRADE, 1990, p. 47).

O "Manifesto antropofágico" modernista, criado por Oswald de Andrade na década de 1920, fazia um chamado à devoração cultural das técnicas importadas. Estas, reelaboradas com autonomia, poderiam se converter em produto de exportação. Trata-se de uma proposição de deglutição crítica do outro que, àqueles olhos, eram os modernos e civilizados. Essa dinâmica de apropriação pode ser encontrada no trabalho colaborativo de um laboratório, pode-se dizer, repleto de estômagos em processo de digestão. Mas já não se trata propriamente de devorar técnicas importadas, mas sim de devorar o outro, aquilo que não sou ou aquilo que não é meu.

Assim, podemos ver os laboratórios cidadãos convertendo e assimilando de tudo um pouco, e ainda, desfrutando da criação como um todo sem perder, nessa deglutição, nem sequer, uma parte. Não podemos afirmar que os interessa propriamente a finalidade deste processo digestivo, porque o meio, por fim, guarda grande porção daquilo que chamamos inovação.

A antropofagia nos serve de referência porque nos fala, sobretudo, de nossa relação com o diferente e de nossa capacidade de elaboração diante das novas informações que nos chegam. Ainda hoje, esse tipo de dinâmica parece ser fundamental, e quando o tema é tecnologia, esta talvez seja especialmente relevante.

Posso imaginar os laboratórios sul-americanos como grandes sistemas digestivos de informações vindas de diferentes partes. Com diferentes técnicas e diversas tecnologias sendo assimiladas e reelaboradas, para em seguida serem expressas - e por que não também exportadas? - de maneiras genuínas e pertinentes para outras tantas realidades.

É justamente no contexto sul-americano que esse tipo de laboratório-estômago ganha uma face radicalmente comunitária, trazendo-nos exemplos claros das 
dimensões coletiva e transindividual, tão caras aos processos tecnossociais. Podemos observar isso em laboratórios que ocorrem em diferentes escalas, como é o caso do Laboratório de Inovação Cidadã (labiCCo), realizado em Cartagena das Índias, na Colômbia, ou do Interactivos?'16: Água e Autonomia, realizado na APA da Serrinha do Alambari, serra da Mantiqueira, Brasil.

O primeiro caso é o labicCCo, que teve sua terceira edição em Cartagena das Índias na Colômbia, no ano de 2016. Ele está sob a direção de Pablo Pascale e Mariana Cancela, e nessa edição foi apoiado pelo Ministério da Cultura da Colômbia, por meio da figura de Moisés Medrano. Esse laboratório teve especialmente um grande avanço no que diz respeito à tecnologia social. A metodologia contava com a presença de mediadores comunitários da cidade de Cartagena, que começaram a trabalhar com antecedência para fazer a ponte entre o laboratório e as comunidades. Os mediadores deveriam apresentar as propostas selecionadas às comunidades e fazer toda a gente que foi ao lab transitar pelos bairros e comunidades de Cartagena incluindo comunidades/cidades dos arredores - para, a partir e no meio desse contato, desenvolverem seus projetos. Diferentes comunidades interessadas nas propostas foram ao lab como colaboradoras ou deixaram que os participantes do lab trabalhassem em seu território. Com isso, os projetos se tornaram mais realistas, e os debates e as decisões, mais complexos.

Destaco a proposta "Develando humanidad", projeto do qual foi mentora Nemecio Berrio Guerrero e integrantes da companhia Permanencias - dança afrocolombiana contemporânea. Foram os proponentes que contaram com uma equipe de bailarinos, psicólogos, assistentes sociais e pesquisadoras da dança e do sistema carcerário, como colaboradoras. "Develando humanidad" é um projeto com mulheres em situação de confinamento, muitas delas afrodescendentes, e a penitenciária San Diego em Cartagena foi o local escolhido para trabalhar. O objetivo era promover insumos de formação artística, sensível, humana e criativa para somar ao processo de ressocialização e reinserção dessas mulheres na sociedade, além de oferecer um trabalho de autorreconhecimento como seres humanos e seres políticos, parte de uma sociedade que as necessita.

A principio, o projeto parecia ter a necessidade de se adaptar à dinâmica do lab, mas por fim foi o lab que se adaptou às dinâmicas do projeto, desenvolvido na maior parte do tempo fora do espaço laboratorial e dentro do presídio, sob negociações de todo tipo, incluindo a permissão de saída das mulheres em situação de cárcere para o edifício da Cooperação Espanhola em Cartagena, para que ali realizassem uma apresentação final do trabalho que desenvolveram com a companhia de dança.

Durante a prática com essas mulheres, havia uma série de acordos consentidos e éticas construídas conjuntamente. O trabalho realizado com essas mulheres foi impactante - tão positivo e profissional, nos mínimos detalhes, que mal se podia acreditar que todas as mulheres que dançavam diante de nossos olhos estavam desprovidas de liberdade. Tivemos ali a prova de que o projeto teve sua primeira fase muito bem-sucedida e que tem ainda condições de ser uma ótima ferramenta de tecnologia social - empática - para trabalhar com temas bastante complexos de serem resolvidos.

Outro ocorrido que me chamou a atenção nesse laboratório foram os acontecimentos decorrentes da presença de diferentes etnias indígenas, que desestabilizavam os hábitos mais comuns de algumas das equipes. As equipes lideradas ou compostas por integrantes de etnias indígenas apresentaram diferentes e proveitosas crises. A permanência dessas pessoas no cotidiano do lab nos trazia 
questionamentos relativos à temporalidade convencional estabelecida, aos modelos de representação, às diferentes éticas, revelando-nos, por vezes, grandes abismos, mas também proporcionando a emergência da criação de pontes possíveis entre esses mundos.

O projeto "Somos de Aquí" propunha sistematizar calendários de cultivo agroecológicos, adaptados às novas condições derivadas do câmbio climático, por meio do trabalho com comunidades indígenas colombianas e da conjunção de tecnologias digitais e saberes ancestrais. Essa proposta foi realizada por Omar, líder de uma comunidade indígena de Nodo de los Pastos. Como colaboradores, havia outra liderança indígena Mapuche e engenheiros agrônomos, uma designer e um programador. Podia-se observar a habilidade que a equipe possuía com metodologias de incursão social, enquanto que, ao mesmo tempo, um abismo comunicacional ia se abrindo entre o trabalho de campo e a sua execução tecnológica. No decorrer do lab, esse grupo nos ensinou muito sobre como comunicar universos radicalmente diferentes.

O ultimo exemplo deste lab é "Gente, una fuente tipográfica digital para la comunidad Wounaan". O projeto se desenvolveu com a colaboração de um professor indígena Wounaan e diferentes especialistas, uma tipografia digital para ser difundida inicialmente em escolas e incluída na Wikipédia. Eles consideravam que havia um risco de extinção da cultura indígena Wounaan, em parte devido ao fato de que não possuem digitalizada sua fonte tipográfica, fazendo com que os jovens não possam escrever em sua língua nos meios digitais. A presença de um Wounaan na equipe desestabilizou os aparatos éticos do grupo, levantando complexos questionamentos sobre representatividade, utilidade/usabilidade e prioridade. Foi necessário criar resiliência para transpor a crise e chegar, enfim, a diferentes protótipos finais muito mais interessantes e "eficientes" do que se havia pensado anteriormente.

O segundo caso foi o Interactivos?'16: Água e Autonomia, desenvolvido por uma jovem equipe de artistas e engenheiros. Trata-se de um laboratório colaborativo de desenvolvimento de projetos que pretendeu ser uma plataforma autônoma de estudos sobre hidrologia, incentivando o cruzamento entre os saberes populares, científicos, técnicos e artísticos na proposição de soluções para as questões da água em diversos âmbitos, por meio de uma perspectiva cidadã. Um dos objetivos fundamentais do programa é fomentar o desenvolvimento, a difusão e o livre acesso às redes de colaboração e conhecimento. Para tal, a edição propôs o acolhimento de projetos que tivessem como objetivo experimentar proposições e soluções relativas aos problemas que enfrentamos, como a escassez da água e o descuido na sua utilização, considerando a água potável para consumo humano e consumo animal, e a água destinada para distintos usos: consumo doméstico, consumo agrícola, consumo industrial e uso em atividades recreativas.

O Interactivos foi desenvolvido na Serrinha do Alambari, parte integrante de uma APA situada no município de Resende, no estado do Rio de Janeiro, na encosta leste do Parque Nacional de Itatiaia, serra da Mantiqueira. Essa área tem a particularidade de integrar zona rural e zona de proteção ambiental. A Serrinha conta com cerca de 1.000 habitantes e possui diferentes atividades econômicas: piscicultura, manejo da juçara, cervejaria, pequeno comércio e turismo. A APA da Serrinha do Alambari protege a parte alta das microbacias dos rios Alambari e Pirapitinga. Sua área total corresponde a 4.500 hectares, e o território onde está inserida é vizinho de um polo industrial localizado às margens do rio Paraíba do Sul e da autoestrada Presidente Dutra, que conecta a cidade do Rio de janeiro à cidade de São Paulo. 
O laboratório contou com propostas de diversas áreas de interesse, incluindo artes, tecnologias, tecnologias sociais, ciências humanas e exatas, engenharias, entre outras. As propostas recebidas deveriam criar uma interação entre diferentes áreas que se complementam dentro da dinâmica sistêmica da água (populações, agricultura, contexto industrial, ecossistemas), por meio de uma plataforma de troca de informações e tecnologias sobre o manejo consciente e sustentável da água.

Foram selecionadas cinco propostas por intermédio de uma chamada pública para projetos. As propostas selecionadas foram desenvolvidas no período de 12 dias, cada uma delas contando com o auxílio de três colaboradoras/es, acompanhamento técnico e a presença de uma mediadora local, moradora da Serrinha. Cada grupo de trabalho desenvolveu, para o território da Serrinha do Alambari, um produto mínimo viável ou um protótipo. Os projetos foram: "Sistema integrado de saneamento ecológico"; "Sistemas agroflorestais como estratégia para a conservação de matas ciliares e nascentes"; "LED liquids entropy machine // DEL dispositivo de entropia de líquidos"; "Sensores - extensões da percepção e interfaces biológica-eletrônica" e por fim, "Drink me - a fresh water story using data and interactive fiction".

A variedade de propostas colaborou para a interação do projeto na comunidade, atingindo desde jovens da escola pública, passando pela associação comunitária e a secretaria de meio ambiente, até os sitiantes e moradores locais. Além da participação do curso de engenharia química da Universidade Estadual do Rio de Janeiro, parte do campus de Resende.

As pessoas se sentiram confortáveis para se engajar, ajudar e colaborar no desenvolvimento dos projetos, inclusive tomando decisões a respeito de temas que também eram do interesse de todos. A precisão de certa vulnerabilidade na apresentação das questões que deveriam ser direcionadas à comunidade e a empatia em relação ao tema foram fatores importantes para a integração. A referência à vulnerabilidade se faz não pela ideia de fraqueza, mas sim pela ideia de abertura.

Ambas as iniciativas, Laboratório de Inovação Cidadã e Interactivos'16: Água e Autonomia, realizadas em 2016, tiveram o desafio de promover espaços laboratoriais para as comunidades, e o êxito alcançado veio como consequência, sobretudo, da empatia entre os projetos e as pessoas envolvidas. Quando uma comunidade acolhe um laboratório é que a deglutição começa e, então, os estômagos começam a trabalhar para a materialização de desejos comuns.

Concluindo, o contraste entre realidades e subjetividades é constante nas instâncias de um espaço aberto. Como dispositivos agenciadores de diferenças e de transformações de ideias e de indivíduos, os laboratórios podem atuar diante das intermináveis demandas do intenso momento de mudança pelo qual temos passado. Talvez garantir espaços para processos seja fundamental para a atualização constante dos saberes e práticas que nos atravessam. A experimentação estrutura criticamente indivíduos e comunidade, e a tomada de consciência culmina a partir do acúmulo de processos experimentais.

As colaboradoras e os colaboradores podem vir a ser protagonistas dos laboratórios cidadãos. E no contexto heterogêneo e transdisciplinar em que se dá o debate e a criação, o comum pode se estabelecer como um horizonte por meio de ato criativo, isto é, do nascimento e desenvolvimento das ideias, da maneira de fazer. A necessidade de criar algo é o que moverá os presentes a compartilhar um mesmo espaço, e são as atividades relativas à pesquisa e ao desenvolvimento de cada projeto que promoverão a riqueza da coexistência: o convívio e a troca. 
Já a consciência sobre o direito do comum se estabelece quando há, entre todos, o direito à governança de recursos. Como acontece em muitas sociedades rurais baseadas na produção familiar, onde a terra cultivada é de muitos camponeses - isto é, o território é comum a um grupo (commons), e não delimitado ou valorizado pelo uso de cercas -, as divisões consensuais e o regime do comum são práticas fundamentais para esses espaços de criação (CASTRO, 2008, p. 182).

No entanto, o contexto neoliberal em que vivemos nos leva a problematizar todo formato aberto de produção de saberes, fazendo-nos pensar nas alternativas possíveis para que nossa produção, e com ela nossos investimentos individuais e coletivos, não venham a ser captados por grandes corporações que tenham condições de transformar e usar a força de trabalho e a produção de pensamento alheia em capital privado. O mesmo poderia acontecer com os Estados, são muitas as narrativas de opressão baseadas em dados e pesquisas abertas.

Os laboratórios, se pensados como instâncias mais corporificadas e menos institucionalizadas, podem funcionar como um dispositivo de proliferação de fluxos de informações, até que estas ganhem forma. O trabalho colaborativo parece ser um intercâmbio extremo e intenso, com muitas alteridades que se unem por uma ideia comum. Para tal, basta deixar que os projetos sejam sutilmente vulneráveis, isto é, estabelecer relação de escuta, deixar espaço, ventilar, criar hiatos para serem preenchidos por outros saberes. A estruturação de certa vulnerabilidade pode ser um interessante ponto de partida na construção de projetos empáticos que desejam ser do comum, "para si" e também "para outros".

Artigo recebido em 31/01/2017 e aprovado em 19/05/2017.

\section{REFERÊNCIAS}

III LABORATÓRIO IBEROAMERICANO DE INNOVACIÓN CIDADANA. Cartagena de las Indias, 2016, Colômbia. Disponível em:<http://www.ciudadania20.org/es/3rd-iberoamerican-civic-innovation-lab-labicco/>.

ANDRADE, Oswald de. A utopia antropofágica. São Paulo: Globo: Secretaria de Estado da Cultura, 1990. (Obras Completas de Oswald de Andrade).

BRAZILEIRO, Ricardo. A inovação e o dilema dasandbox. 2016. Disponível em: <https://medium.com/@rbrz/a-inova\%C3\%A7\%C3\%A30-e-o-dilema-da-sandboxd3882c20164a>. Acesso em: abr. 2017.

CASTRO, Eduardo Viveiros de. Sobre os modos de existência dos coletivos extramodernos: Bruno Latour e as cosmopolíticas ameríndias. Projeto de pesquisa. Disponível em: <https://ufrj.academia.edu/EVdeCastro>. Acesso em: mar. 2017

. Eduardo Viveiros de Castro. Organização de Renato Sztutman. Rio de Janeiro: Beco do Azougue, 2008. (Encontros).

ESCÓSSIA, Liliana da. Individuação e informação em Gilbert Simondon. Informática na Educação: teoria \& prática, Porto Alegre, v. 15, n. 1, p. 19-30, jan./jun. 2012.

INTERACTIVOS?'16 ÁGUA E AUTONOMIA. Serrinha do Alambari, 2016. Disponível em: <http://interactivos16.info/;http://doc.interactivos16.info/>.

SIMONDON, G. A gênese do indivíduo. Cadernos de Subjetividade, São Paulo: Núcleo 
de Estudos da Subjetividade do Programa de Estudos Pós-Graduados em Psicologia Clínica da PUC-SP, v.1, n.1, 2003. Número especial: O reencantamento do concreto.

- La individuación a la luz de las nociones de forma y de información. Buenos Aires: La Cebra: Cactus, 2009. 